\title{
Stakeholder perceptions of research options to improve nutritional status in Uganda
}

David Lubogo and Christopher Garimoi Orach*

\begin{abstract}
Background: Malnutrition is a major public health problem in sub-Saharan African countries including Uganda. The objective of this study was to evaluate the relevance of the current research options towards improving nutrition status in Uganda.

Methods: We used the Multi Criteria Mapping (MCM) technique for data collection. Both qualitative and quantitative data were collected. The qualitative data were gathered while quantitative scores were assigned and the qualitative data were in the form of reasons given for the scores assigned by the interviewees to each option under each criterion. We interviewed 16 high level representatives of six different stakeholder groups including health professionals, food industry, government, civil society, academics and research funders. Each stakeholder appraised six types of research options including; ecological nutrition, community nutrition interventions, nutritional epidemiology, behavioural nutrition, clinical/therapeutic nutrition and molecular nutrition on how they could best address malnutrition in Uganda. The criteria used by the interviewees to appraise the research options were categorised by the research team into five types, namely: cost effectiveness, practical feasibility, impact, social acceptability and research efficacy. Data were captured using the 'Multi Criteria Mapper' software and analysed using the 'MCM Analyst' software.
\end{abstract}

Results: The most prioritised nutrition research options intended to improve nutrition status in Uganda were firstly applied community nutrition, secondly behavioural nutrition and thirdly ecological nutrition. Applied community nutrition was regarded as low cost and responsive to community problems. Behavioural nutrition was considered to be highly acceptable to communities and the country has the necessary expertise for its implementation. Ecological nutrition was considered to be in line with the countries' development priorities in agriculture and environment. Molecular nutrition research was regarded as very costly to implement, had ethical dilemmas and was therefore the least prioritised.

Conclusions: The research options considered most appropriate towards improving nutrition status in Uganda were community nutrition intervention and behavioural nutrition. Molecular nutrition was considered the least appropriate research option owing to costs and ethical dilemmas. Stakeholders should consider supporting community and behavioural nutrition research interventions in Uganda.

Keywords: Stakeholder, Perceptions, Research method, Research policy, Malnutrition, Uganda

\footnotetext{
* Correspondence: cgorach@musph.ac.ug

Department of Community Health and Behavioural Sciences, Makerere

University, College of Health Sciences, School of Public Health, P. O. Box 7072,

Kampala, Uganda
} 


\section{Background}

Malnutrition is a major public health problem in subSaharan African countries including Uganda. Sub-Saharan Africa has the highest prevalence of undernourishment inability to meet dietary energy requirements in the population estimated at $24.8 \%$ [1]. About $36 \%$ of children under five are stunted and $26 \%$ are underweight [2].

While Uganda has registered an impressive economic growth rate averaging $7 \%$ per annum in the last 10 years [3], progress towards reducing malnutrition has remained disturbingly slow. In Uganda, $33 \%$ of children under 5 are stunted, $14 \%$ are underweight while $5 \%$ are wasted [4]. Anaemia affects half (50\%) of children 6-59 months old. About one in four women in the reproductive age (15-49 years) are anaemic [4], while $35.8 \%$ of children under five are deficient of vitamin A [5].

Despite the high cost of malnutrition globally $[6,7]$, there has been limited investment in nutrition. Studies indicate that the current global investment in nutrition have not matched the size of the nutrition challenge $[8,9]$. There is evidence that returns on investments in nutrition are high [10,11] and benefit future generations [7]. Nutrition should be prioritised at national and subnational levels because of its importance in human, social and economic development [12]. Furthermore, investment in nutrition is a necessary prerequisite towards the attainment of the Sustainable Development Goals (SDGs), especially the second goal on ending hunger, achieving food security and improving nutrition, and promoting sustainable agriculture by the year 2030 [13].

In Uganda, nutrition research is mainly funded by the development partners (donors), international non governmental organizations (NGO's) and only to a limited extent by the government of Uganda. Most funding for nutrition research in African countries is obtained from international NGOs and donors. These external funders influence the agenda for nutrition research in accordance with their own interests $[14,15]$.

A World Bank report recommends countries to take lead in their development agendas and strengthen the evidence base for investing in nutrition [10]. Countries need to invest in locally appropriate, sustainable and effective, research based, interventions [14]. It is acknowledged that countries have a reservoir of experience and expertise that should be tapped to address nutrition challenges [12]. There are several interventions that can be effectively implemented locally including community based interventions [11]. For instance, communities can be sensitised to make use of traditional foods which are locally available and cheaper. Additionally, there is need to develop the research capacity of local researchers to meet the current and future research needs of the country [14]. This requires commitment and efforts from all stakeholders owing to the fact that nutrition programs are considered low priority for both governments and development partners [10]. The objective of this study was to identify priority areas for nutrition research so as to design effective interventions to address malnutrition in Uganda.

\section{Methods}

\section{Study design and setting}

We conducted a cross section study between June and November 2011. Both qualitative and quantitative data were collected using the MCM technique [16]. The qualitative data were gathered while quantitative scores were assigned and the qualitative data were in the form of reasons given for the scores assigned by the interviewees to each option under each criterion. A total of 16 stakeholders selected from six different stakeholder groups in Uganda were interviewed. The stakeholders comprised health professionals, food industry, government, civil society, academics and research funders. Each stakeholder appraised six types of research options namely; ecological nutrition, community nutrition interventions, nutritional epidemiology, behavioural nutrition, clinical/therapeutic nutrition and molecular nutrition (Table 1), for how they could best address malnutrition in Uganda. The six types of research options were chosen by the project consortium team members following extensive meetings held in 2011. The research team then selected the research options taking into consideration the current nutrition research domains and the relevance of those research domains in the national and regional contexts. The participants were asked what they would consider as measures of performance by which the six types of research options would be judged. Using the participant's responses, a criterion was generated by the research team that included; cost effectiveness, practical feasibility, impact, social acceptability and research efficacy (Table 2).

\section{Study population}

We identified sixteen stakeholders from six stakeholder groups including civil society, food industry, government, health professionals, researchers/academics and research funders (Table 3). These stakeholders represented institutions that have a significant role to play in nutrition research.

\section{Selection of participants}

We identified and selected high ranking individuals to represent their stakeholder groups, taking into consideration their positions in terms of conducting, utilising, funding, planning research and contributing to nutrition research policy development. This was done to enable generation of relevant, reliable, and comprehensive viewpoints on nutrition research policy. The research team 
Table 1 Types of research options and operational definitions

\begin{tabular}{ll}
\hline Type of option & Operational definition \\
\hline 1. Ecological research & $\begin{array}{l}\text { Nutrition research in Africa should include ecological approaches to focus on the environmental threats } \\
\text { (climate change, food scarcity) that Africa will face and their impact on nutritional status. This will } \\
\text { involve conducting integrated research with nutritionists, climate scientists and agricultural researchers } \\
\text { to improve the way land is used and our understanding of how communities respond to various } \\
\text { exposures. }\end{array}$
\end{tabular}

2. Community nutrition interventions

3. Nutritional epidemiology

4. Behavioural nutrition

5. Therapeutic/clinical nutrition

6. Molecular nutrition (laboratory based)
Nutrition research in Africa should prioritise improving the evidence base for effective interventions to improve the nutritional status of African populations using a participatory approach. This would require the implementation, monitoring and evaluation of nutrition interventions.

To investigate diet-disease relationships, studies could include: a) research synthesis such as systematic reviews, b) conducting longitudinal studies, c) using secondary data that are available in a country related to nutrition related deaths, hospital admissions and treatment to guide planned interventions.

Nutrition research should give priority to conducting nutrition research that incorporates other disciplines, especially the social, anthropological and behavioural sciences, such as investigating attitudes to address current public health problems.

Nutrition research in Africa should focus on improving the ways that nutritional problems are managed. This involves treating/managing obesity, under nutrition, micronutrient deficiencies, other nutritionrelated diseases and HIV. This may include the use of supplements and human feeding trials.

Nutrition research in Africa should focus on investing in basic nutrition science using new molecular, genetic and biochemical approaches, such as nutrigenomics so that science in Africa can develop technological approaches to address Africa's nutritional problems. consulted relevant literature and held discussions with potential participants to determine their suitability for the interview. After identifying participants for the six stakeholder groups, we asked them to refer us to other stakeholders within their stakeholder group until we generated a list of 16 stakeholders whom we identified and interviewed.

\section{Data collection procedure}

We used the Multi Criteria Analyst software to assess stakeholder's perspectives on how effectively the six types of research options or methodologies could address the problem of malnutrition in Uganda. Sixteen stakeholders comprising six stakeholder groups (Table 3) were interviewed. The interviews lasted approximately
2-3 h per stakeholder. We explained the MCM tool and the research options to each one of the 16 participants before inviting them to appraise the research options. The interviewees were free to add additional research options of their choice.

We conducted the interviews either at the place of work or at a convenient venue preferred by the participants. We used a laptop computer loaded with the Multi Criteria Mapper software package to capture the interview proceedings. The interviews were conducted by two senior academics in Uganda. The researchers were trained for a week on the MCM methodology in Tanzania in March 2011 and in South Africa during April - May 2011. The training and use of senior academics ensured consistency in data collection and access to high level

Table 2 Criteria chosen to appraise six research options by participants in Uganda

\begin{tabular}{ll}
\hline Criterion & Explanation of the criteria chosen to evaluate research options in Uganda \\
\hline 1. Impact (on nutrition and society) & $\begin{array}{l}\text { Impact on society: reduces poverty and increases equity; empowerment; participation; gives benefits to } \\
\text { environment, food rights; Will it work to improve nutritional status? Time lag for impact of findings, } \\
\text { sustainability, addresses an important issue/pertinence; reaches the right target groups, especially women and } \\
\text { children and reaches minority and vulnerable sub-populations; broad reach of findings in population; findings } \\
\text { can be scaled up or applied in reality. }\end{array}$
\end{tabular}

2. Research efficacy

Quality of research: rigour, representativeness, measurable; originality; multidisciplinary; applied research focus; availability of baseline data; relevance; uses existing evidence; can be evaluated/monitored; publication of results to academic audience; time that research takes to conduct; contribution to new knowledge.

3. Cost

4. Practical feasibility

5. Social acceptability
Cost of doing the research; cost-effectiveness; cost of applying the research findings.

Can research be conducted politically, technically? Policy environment for supporting it. Cooperation of agencies, across departments and sectors; supported by government and at policy level. Technical feasibility, can be implemented, is practical- IT infrastructure, equipment, buildings, access to facilities. Is the human capacity available- in terms of skills/good management structures.

Social, cultural and individual acceptability; popularity; community participation and consultation both before and after research findings are known; culturally relevant; evidence it meets local needs; adapted to communicate with illiterate populations. 
Table 3 Stakeholder groups and categories of institutions (source of participants)

Stakeholder groups (A-E) and category of institutions/source of participants (1-16)

A) Health professionals

1. Clinicians-medical research council/public health association

2. Nutritionists via a nutrition society/association on the ground

B) Food industry

3) Small and medium size agro food industry

4) Large scale food industry

C) Government

5) Ministry of health/nutrition

6) Ministry of Agriculture/food production

7) Ministry of social development/community

8) Ministry of higher education/research

D) Civil society

9) Public interest NGO - health/food group

10) Citizens association/representing public food health and safety

E). Research/academic

11. Nutrition researcher

12. Agricultural researcher

13. Social sciences researcher

F) Research funders

14. World bank/WHO

15. NEPAD/USAID/Others

16. United Nations agencies

Keys: NGO Non Governmental Organisation, UNICEF United Nations Children's Fund, NEPAD New Partnership for Africa's Development, USAID United States Agency for International Development, WHO World Health Organization

stakeholders through their professional networks. The stakeholder groups and the categories of institutions of the participants interviewed are shown in Table 3.

\section{Appraisal of research options}

The MCM technique permitted participants to select their own preferred criteria for appraising the six research options. The participants chose five criteria namely; impact, practical feasibility, cost, social acceptability and research efficacy to evaluate the research options as shown in Table 2. During the interview, participants were asked to use a given criteria to numerically score each research option. The scoring for the research options were based on a scale of one to ten chosen by the participant. The MCM software normalised these scores to make them comparable.

The interviewer used the MCM software to guide participants in assigning two performance scores to each research option under each criterion. One score was given to reflect the performance of a research option under the most pessimistic and the second score represented the performance under the most optimistic assumptions respectively. The MCM software (http://www.multicriteria-mapping.org/ mc-mapper) then generated bar charts that indicated the overall relative performance of each option as perceived by stakeholders.

\section{Data analysis}

Both quantitative and qualitative MCM data analyses were conducted in parallel as iterative and inductive processes. We used MCM analyst software [17] to create a data base for examining data by stakeholder groups. In MCM analyst, the database containing all data relating to all participants was interlinked through Microsoft Access with text reports of the qualitative data and a spread sheet to process and present quantitative data in the form of charts. The charts were used to show the average of the pessimistic (left-hand end of bar) and optimistic (right -hand end of bar) ranks, i.e. combined weighted scores for all criteria given by all participants. Quantitative data were grouped for the six different stakeholder groups whereas qualitative data shed light on the factors influencing the performance of different research options.

\section{Ethical consideration}

The study was approved by the Makerere University School of Public Health, Higher Degrees, Research and Ethics Committee on 22nd July 2011(IRB00005876, HDREC137) and the Uganda National Council for Science and Technology. All participants provided either written or verbal informed consent.

\section{Results}

\section{Overall ranking of research options}

As shown in Fig. 1, community nutrition intervention, behavioural nutrition and ecological nutrition were the highest ranked research options under optimistic conditions. Molecular nutrition was the lowest ranked research option.

Under pessimistic scenarios, applied community nutrition research still had the highest ranking, followed by nutritional epidemiology, behavioural nutrition and therapeutic/clinical nutrition. Molecular nutrition retained the lowest ranking. Molecular nutrition had low scores under both optimistic and pessimistic conditions suggesting that it was considered of low importance in the settings.

\section{Ranking of nutritional research options by different stakeholders groups \\ Community nutrition intervention}

Figure 2 indicates that the various stakeholder groups ranked community nutrition intervention the highest while molecular nutrition the lowest. Most stakeholders ranked the community nutrition intervention option highest and pointed out that community based interventions provide solutions to community based problems. Moreover, it was regarded as relatively low cost, easy to conduct and with minimal political resistance and interference. Under pessimistic conditions, only the research funders ranked community nutrition option the worst. 

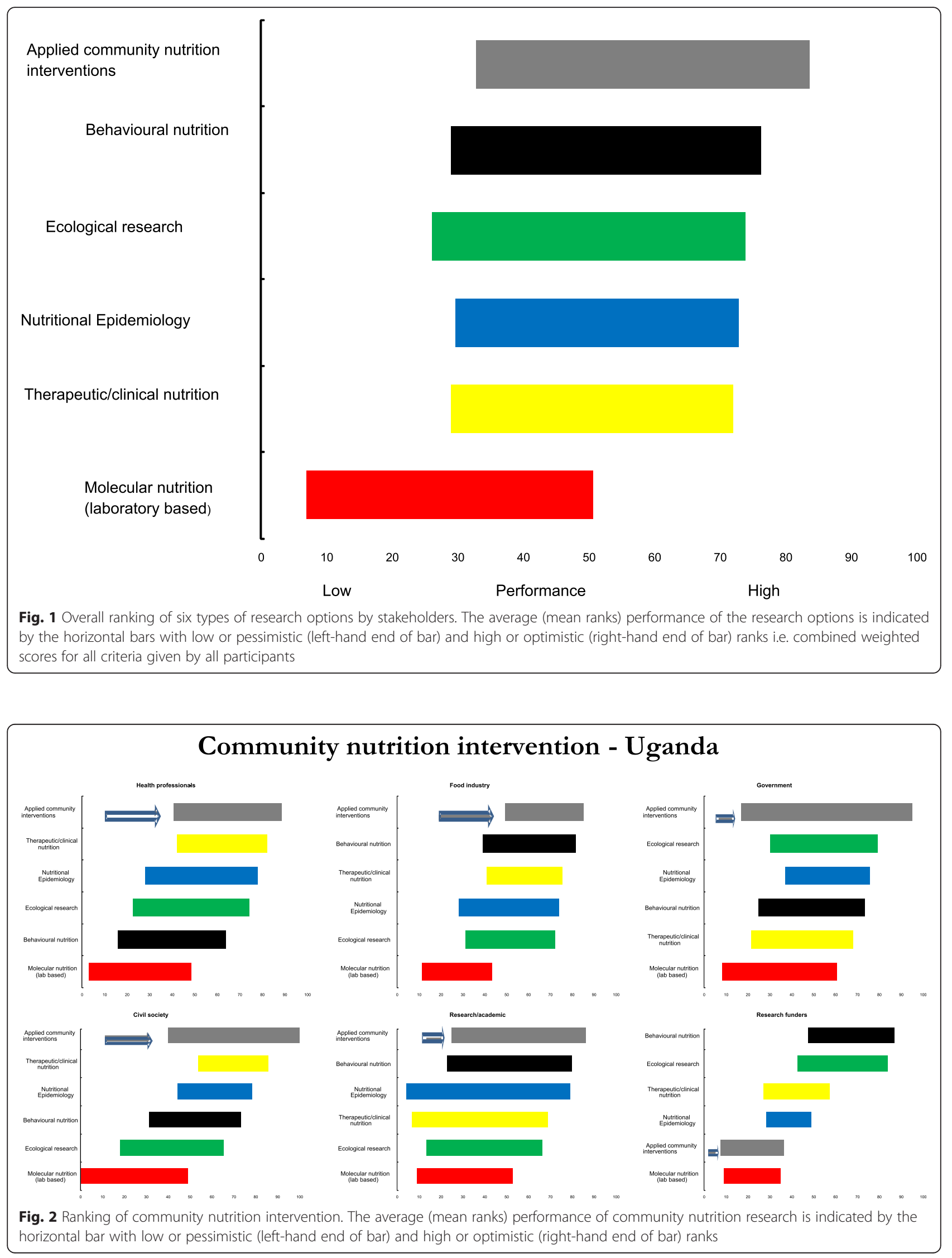
The research funders attributed this low performance to a lack of clear monitoring and evaluation system for community nutrition interventions.

\section{Behavioural nutrition}

Behavioural nutrition research had mixed performance from the different stakeholder groups. It was ranked in the first place by research funders, second by both the food industry and researchers/academics (Fig. 3). According to the three stakeholder groups, Uganda has all the necessary technical expertise to implement behavioural nutrition research and hence the kind of support it generated.

However, health professionals were not particularly keen on behavioural nutrition research and ranked it second last. They pointed out that behavioural research is longitudinal and requires many years of engagement with study subjects, a feature which makes it quite costly to undertake.

\section{Ecological nutrition}

Ecological nutrition research was considered by government and research funders as the second best option, under both optimistic and pessimistic conditions as shown in Fig. 4. The participants attributed the main strength of ecological nutrition to its being in line with the countries' development priorities in agriculture and environment. They stated that it is a pertinent intervention to undertake at a time when the country is experiencing changes in climate. Adding that it can provide opportunities to utilise low cost solutions like tree planting or planting drought resistant crops. This intervention was thus considered to be cost effective in the long term.

\section{Nutritional epidemiology}

As shown in Fig. 5, participants had mixed views on the performance of nutrition epidemiology. The health professionals, government, civil society and researchers/ academics ranked it the third best option. However, the research funders and food industry ranked it the fourth best option. According to the participants, nutrition epidemiology was supported due to its ability to provide information necessary for nutrition planning and surveillance. It also faces limited political interference compared to other research options. However, some stakeholders were concerned that implementation of nutrition epidemiology requires good data management for example health management information system, which they considered to be weak in many districts across the country at the moment.

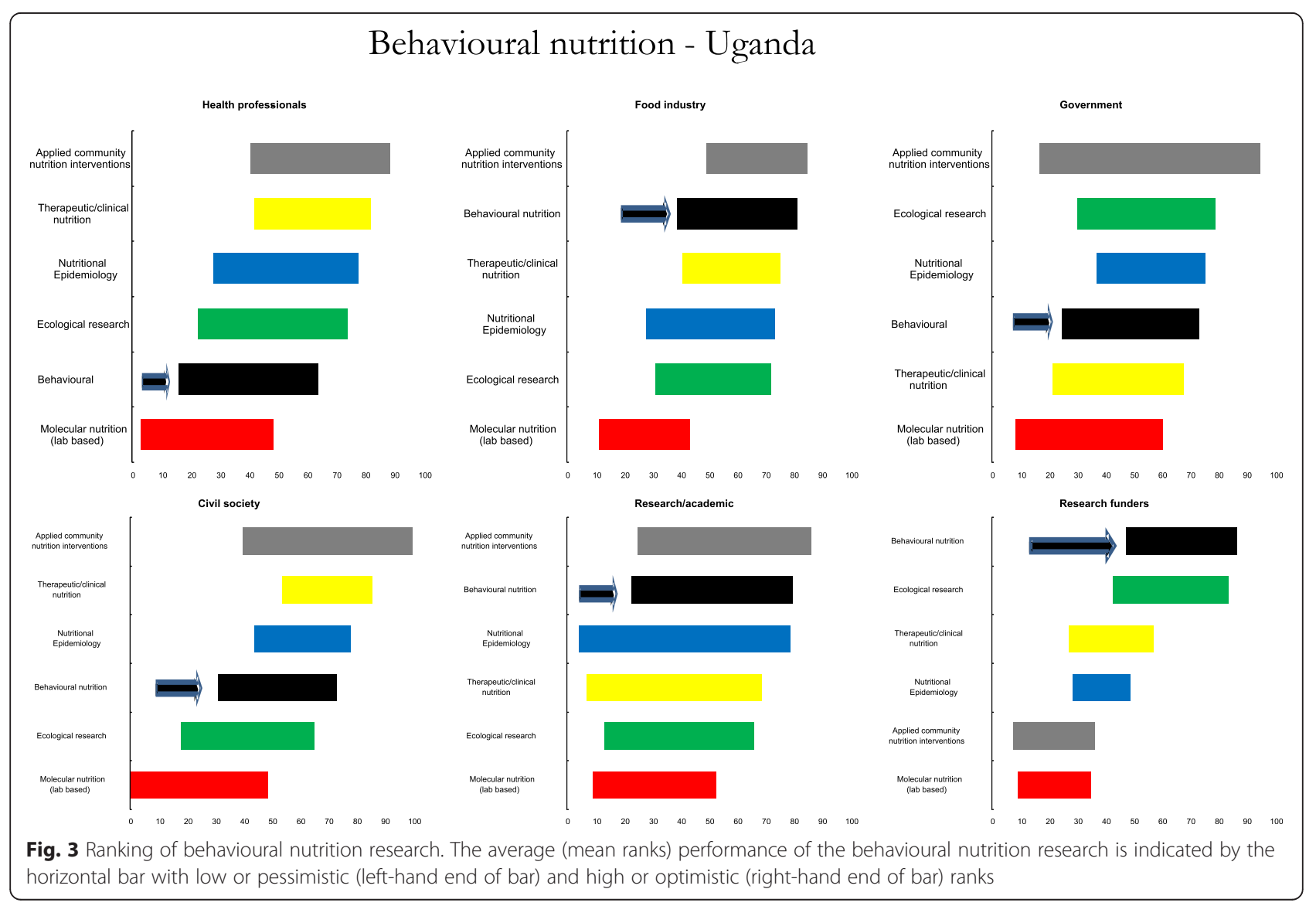



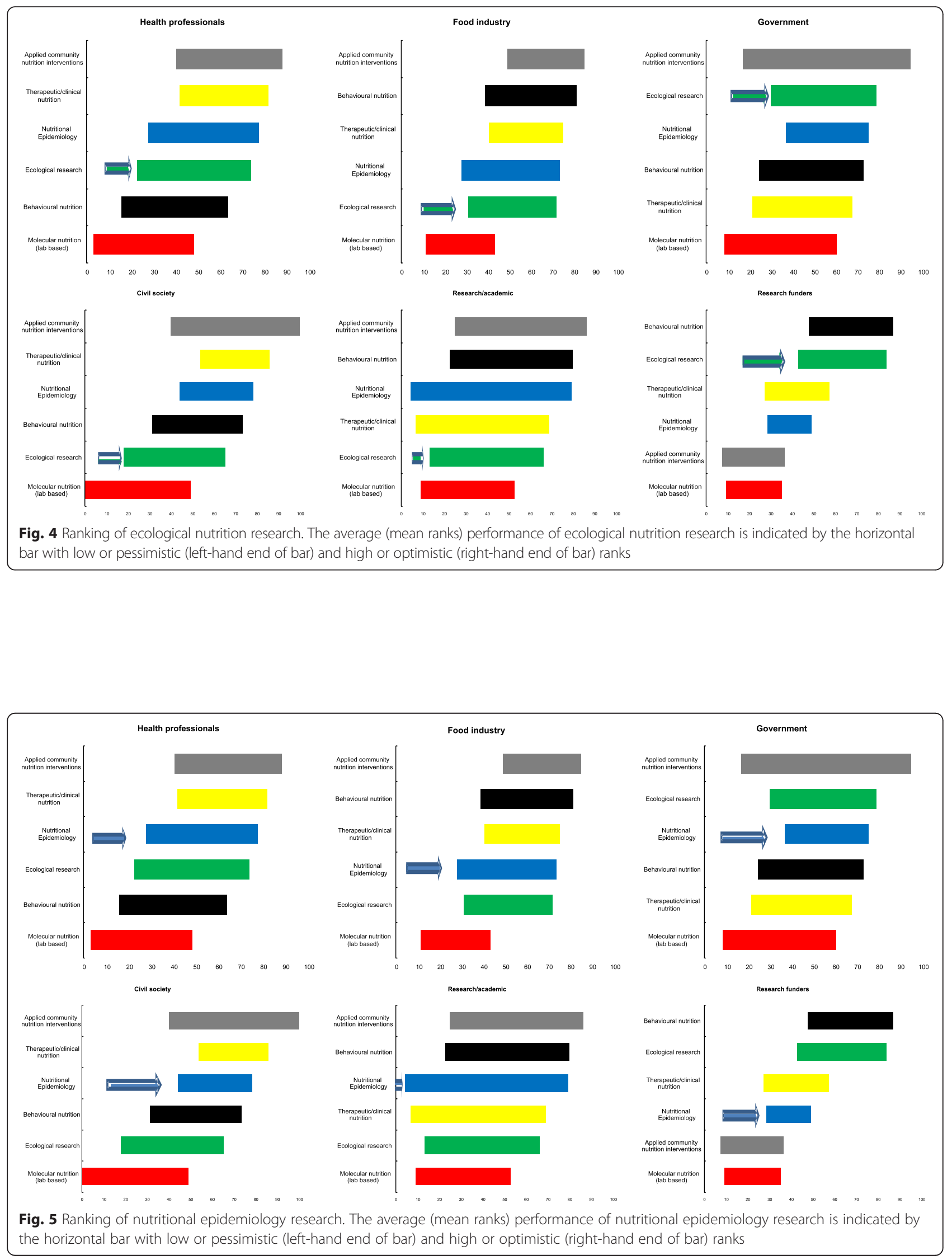


\section{Therapeutic/clinical nutrition}

The study showed variability between stakeholder groups about the performance of therapeutic nutrition research (Fig. 6). The health professionals and civil society scored it the second best option. The participants stated that therapeutic nutrition provides quick and remarkable results for malnourished individuals. They noted that the country has the required technical expertise to implement this intervention. In addition, they stated that therapeutic nutrition enjoys a high level of trust as well as political and community support. However, the major challenge mentioned by the participants was that its implementation is largely facility based and so access to this intervention is limited for the majority of individuals who reside in rural communities where health facilities are few. Another challenge mentioned by the participants is that therapeutic nutrition research focuses on treatment of malnourished individuals as opposed to prevention of malnutrition which according to the participants would be a better intervention.

\section{Molecular nutrition}

As shown in Fig. 7, molecular nutrition was ranked the lowest by all the six stakeholder groups under both optimistic and pessimistic scenarios. However, uncertainty about its performance was low compared to other research options. Although stakeholders recognised this option for its scientific rigor, it was ranked lowest. The participants indicated that this was because of several shortcomings including high cost, ethical dilemmas, limited expertise and equipment to undertake molecular nutrition research.

\section{Ranking of research options by sex}

For both sexes, there was some consistency in the ranking of the research options. Community nutrition intervention was ranked the highest under optimistic scenarios and molecular nutrition was ranked the lowest under both optimist and pessimist scenarios respectively (Fig. 8).

\section{Discussion}

The study revealed that overall, stakeholders appraised community nutrition, behavioural nutrition and ecological nutrition as the three most highly ranked research options towards improving nutritional status while molecular nutrition research option was the lowest. The reasons community nutrition was ranked highest was possibly because it is considered to provide quick solutions to community based nutrition problems and for being relatively low cost and easy to conduct. This implies that in general, stakeholders perceive community nutrition interventions as the most appropriate research option towards addressing the problem of malnutrition in the country. A recent study by Lachat et al., 2014 also revealed that nutrition stakeholders in sub-Saharan Africa identified community nutrition interventions amongst the top priorities for nutrition research to improve nutrition status [18].

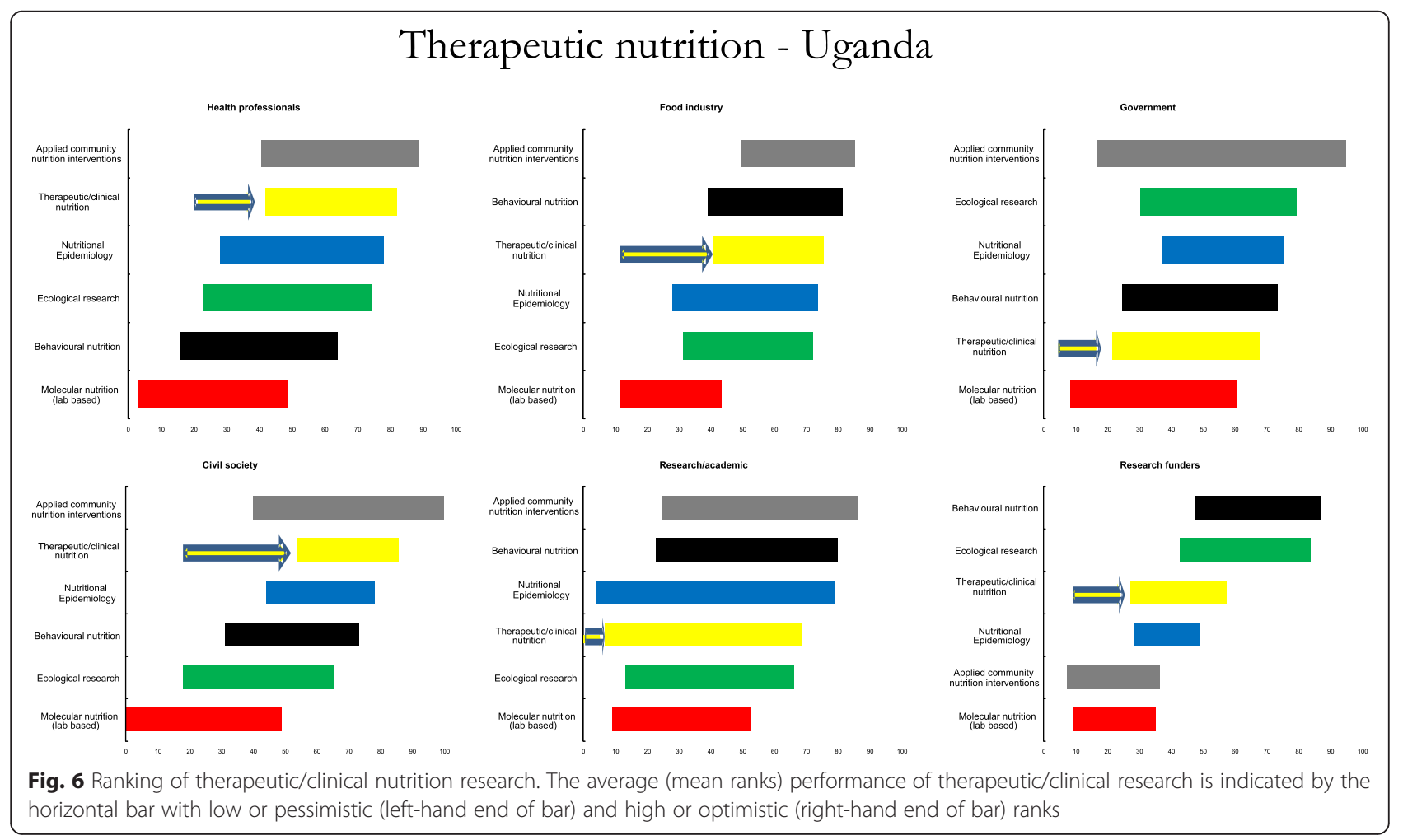




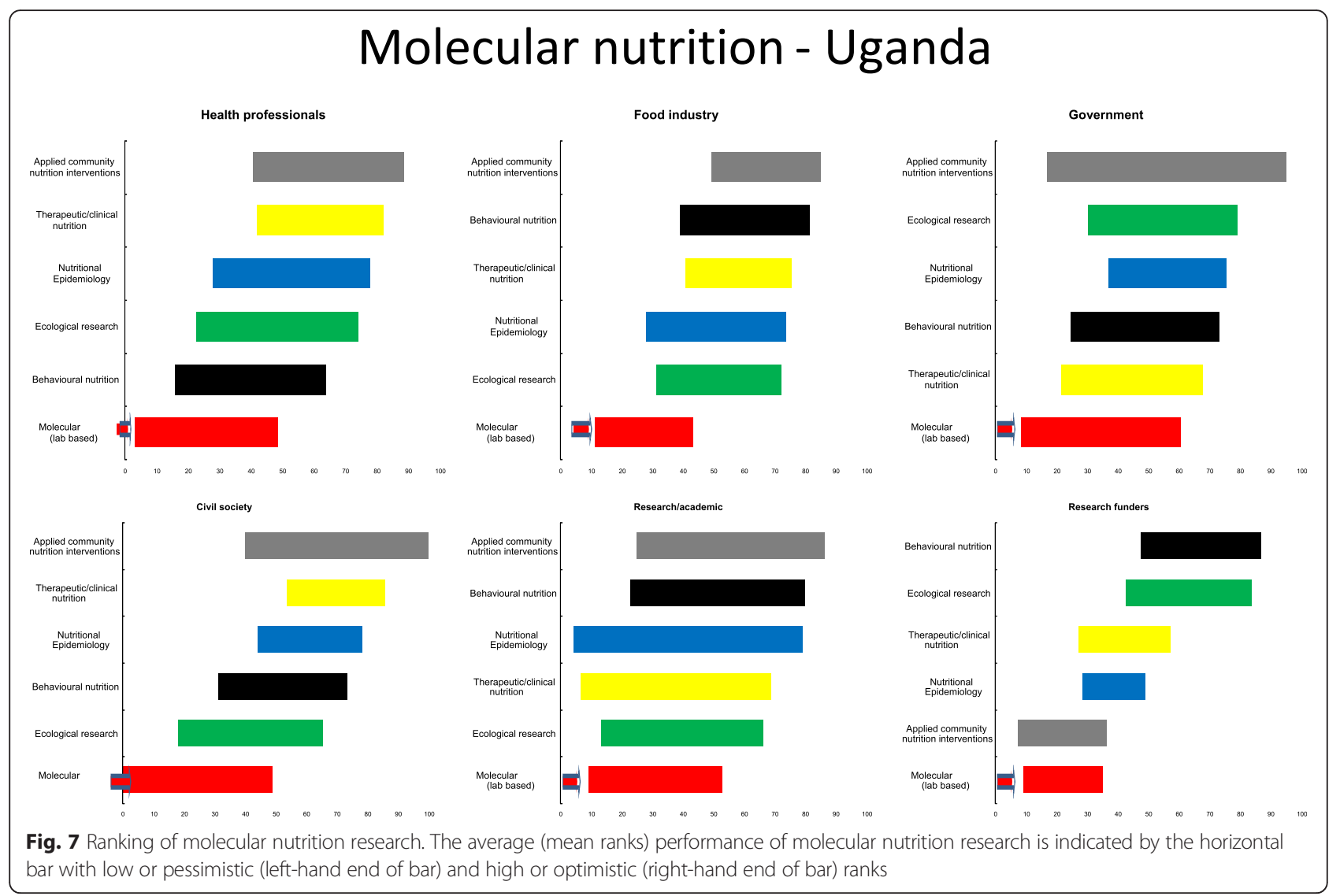

The findings of our study are in agreement with the policy recommendations by the government of Uganda in the Nutrition Action Plan 2011-2016, which outline operational research as a priority investment area. The target research areas identified in the policy document includes improved community and household level food processing for value addition, improved post-harvest handling and storage of food crops, community based school feeding pilot programs and investigation and demonstration of labour-saving technologies for women with young children. Furthermore, emphasis is put on the scale up of cost-effective community-based initiatives for prevention and control of malnutrition through community-based management of acute malnutrition [19].

Behavioural nutrition was the second most highly ranked research option. This may be because the technical experts to implement behavioural nutrition research are available in the country. A study by Holdsworth et al.,

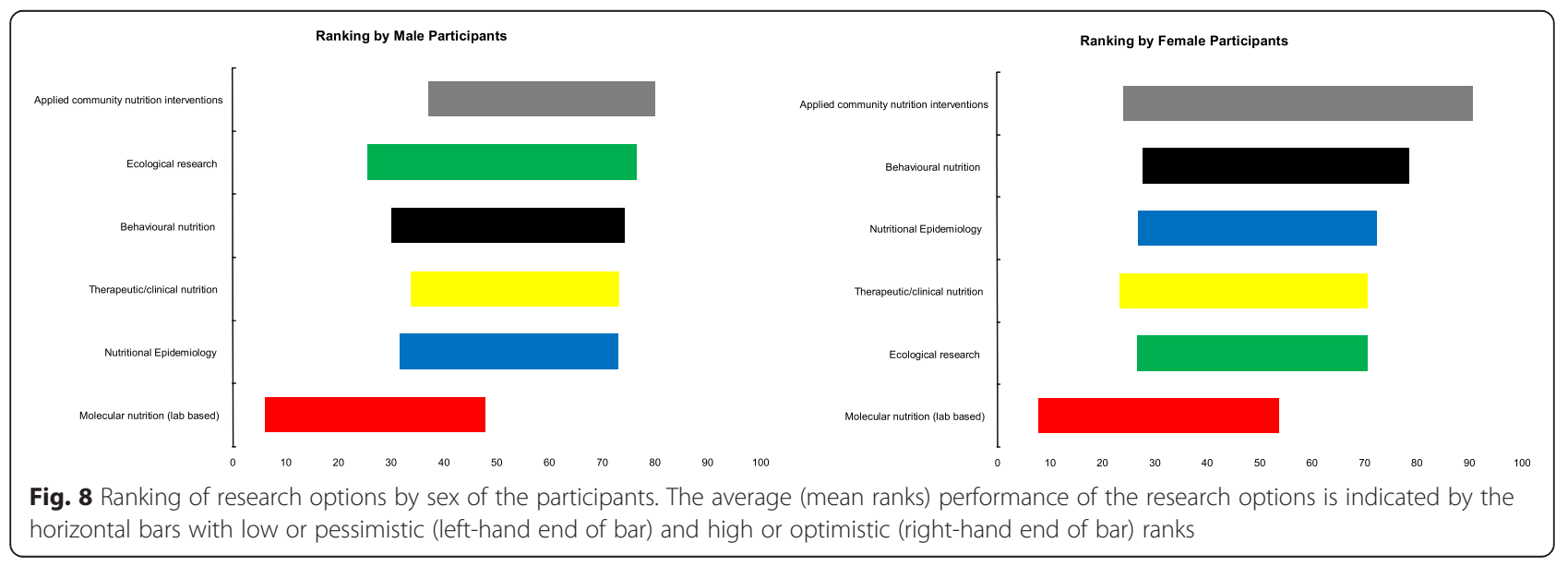


2014 reported that stakeholders in sub-Saharan Africa believe that the technical expertise to conduct behavioural nutrition is widely available in Africa [20]. This implies that given the required resources, implementation of behavioural nutrition research is feasible in the setting.

Ecological nutrition was the third most highly ranked research option. Ecological research option is considered to be in line with the countries' development priorities in agriculture and environment and thus has good political will towards its implementation. This intervention can also be implemented using readily available scientific technologies for instance planting drought resistant crops. Under pessimistic scenarios, ecological nutrition was ranked low, in the fifth position. One possible reason for the low ranking may be because of its inability to provide quick solutions to urgent problems of the day. Another possible reason is that it requires experts across disciplines for it to be implemented effectively. In terms of addressing malnutrition, some researchers contend that it's beneficial in linking agriculture and ecology with human nutrition and health [21], and that ecological nutrition has a significant role to play in directing agricultural interventions for improved nutrition [22].

Nutritional epidemiology was ranked low in the fourth position. This is not surprising because the national health system, which is supposed to capture epidemiological data on nutrition, faces several challenges. For instance there are weaknesses in the health management information systems and the infrastructure to capture data at both the district and sub-district levels is poor. This therefore limits proper use of nutritional epidemiology research. However, nutrition epidemiology ranking improved to second position under pessimistic conditions. This is attributed to the fact that it has less political interference compared to other research options like community nutrition research. Although it's recognised for providing evidence for community nutrition interventions, some African nutrition stakeholders doubt its importance in addressing malnutrition in its own right [20]. However, nutritional epidemiology can provide nutritional surveillance information which is useful in nutrition planning and programming.

The study revealed that therapeutic/clinical nutrition enjoys good political will, public trust and support. However, it was surprisingly ranked low in the second last position. The poor ranking may be attributed to the fact that therapeutic/clinical nutrition studies are usually facility based and the infrastructure to conduct this type of research is inadequate hence limiting its contribution to address nutrition problems in the Ugandan setting.

Molecular nutrition research was the lowest ranked option under both optimistic and pessimistic scenarios in the settings. Molecular nutrition was perceived to have several shortcomings including limited laboratory equipment and technical personnel, the ethical dilemmas associated with its conduct, its high cost of implementation as well as the long period it takes to realise its impact. However, in the developed setting, it can make major contribution to the development of important nutrition interventions [23].

\section{Study limitations}

The study findings should be interpreted with caution. The participants are not representative of all the nutrition stakeholders in Uganda. The study was part of a large multi-country study undertaken in Benin, South Africa, Tanzania and Uganda. Comparatively, a small number of stakeholders contributed their views towards research options to improve nutrition status in the respective countries. However, being a largely qualitative study, the findings provide useful insights that could contribute to addressing the challenges of malnutrition in Uganda.

The participants were selected from amongst those at the highest levels in their organisations. However, their views did not represent the official positions of their organisations. The selection of the participants was done in order to obtain individuals with considerable knowledge and expertise on nutrition research activities and policy issues in their respective organizations. We might have, omitted individuals at lower levels within their organisations with valuable views about nutrition research interventions.

We used purposive sampling to identify stakeholders within their stakeholder groups and thereafter, the selected stakeholders referred the team members to other stakeholders within in their respective stakeholder groups. This may have led to selection of respondents with similar interests in the topic being addressed, while omitting other respondents presumed to have different interests.

We limited the selection of participants to few individuals due to the fact that we had a small sample size to work with. This limited the variety of potential participants. As a result other key stakeholders for instance plant breeders/biotechnologists/plant pathologists in the agricultural sector were not included. However, we think that the respondents we interviewed gave valuable insights given their extensive experience and expertise in their fields.

\section{Conclusions}

The findings of the study suggest that stakeholders consider three nutrition research options namely community nutrition intervention, behavioural nutrition and ecological nutrition as the most important towards improving nutrition status in Uganda. The government 
and development partners should therefore consider supporting the implementation of these research options towards addressing nutrition problems in Uganda.

\section{Abbreviations}

MCM: Multi Criteria Mapping; NGO: Non-Government Organisation; SDGs: Sustainable Development Goals; SUNRAY: Sustainable Nutrition Research for Africa in the Years to come.

\section{Acknowledgments}

The authors would like to express their gratitude to all the partners in the Sustainable Nutrition Research for Africa in the Years to come (SUNRAY) project especially Prof. Patrick Kolsteren, Prof. Michelle Holdsworth and Carl Lachart for their contributions and the various participants who accepted and sacrificed their time to be interviewed. This study was carried out in the framework of the SUNRAY action research project, financed by the 7th Frame work Programme of the European Commission (Grant Agreement Number 266080) [KBBE.2010.2.2-03-Identifying research needs on Malnutrition in Africa]. The funding body had no role in the designing of the study, collection, analysis, interpretation of data or in the writing of the manuscript and the decision to submit the manuscript for publication.

\section{Availability of data}

All relevant data is contained in the manuscript.

\section{Authors' contributions}

CGO and DL designed the study. All authors participated in the data collection, analysis, interpretation and drafting of the manuscript. Both authors read and approved the final manuscript.

\section{Competing interests}

The authors declare that they have no competing interests.

Received: 7 May 2015 Accepted: 17 May 2016

\section{Published online: 19 May 2016}

\section{References}

1. FAO, IFAD, WFP. The state of food insecurity in the world 2013: the multiple dimensions of food security. FAO. 2013. http://www.fao.org/docrep/018/ i3434e/i3434e.pdf. Accessed 13 Apr 2015.

2. AU, UNICEF. A snapshot of the nutrition situation in Africa. African Union Commission, Addis Ababa. 2009. http://www.unicef.org/esaro/A_Snapshot_ of_Nutrition_Situation_in_Africa.pdf. Accessed 13 Apr 2015.

3. MoH. Health sector strategic plan III 2010/11-2014/15 Ministry of Health, Kampala. 2011. http://www.health.go.ug/docs/HSSP_II_2010.pdf. Accessed 13 Apr 2015.

4. UBOS ICF. Uganda demographic and health survey 2011. UBOS and Calverton, Maryland, USA: ICF International Inc., Kampala, Uganda; 2012. http://www.ubos. org/onlinefiles/uploads/ubos/UDHS/UDHS2011.pdf. Accessed 13 Apr 2015.

5. UNSCN. Sixth report on the world nutrition situation: progress in nutrition. Geneva, Switzerland: UNSCN; 2010. http://www.unscn.org/files/Publications/ RWNS6/report/SCN_report.pdf. Accessed 13 Apr 2015.

6. Black RE, Allen LH, Bhutta ZA, Caulfield LE, De Onis M, Ezzati M, et al. Maternal and child undernutrition: global and regional exposures and health consequences. Lancet. 2008;371(9608):243-60.

7. Victora CG, Adair L, Fall C, Hallal PC, Martorell R, Richter L, et al. Maternal and child undernutrition: consequences for adult health and human capital. Lancet. 2008:371(9609):340-57.

8. Rosso J. Investing in nutrition with World Bank assistance. Washington, DC: The World Bank; 1992. http://www-wds.worldbank.org/servlet/ WDSContentServer/W3P//B/1999/10/21/000178830_98101911155019/ Rendered/PDF/multi_page.pdf. Accessed 18 May 2016.

9. Mutuma S, Fremont E. Aid for nutrition. Are we on track to meet the need? 2010 and 2011. Action Against Hunger/ACF International. 2013. http://issuu. com/aah_uk/docs/aid_for_nutrition_2013_final?e=8013468/2898750\#search. Accessed 13 Apr 2015.

10. Shekar M, Heaver R, Lee Y, Nadkarni V, Soletti A, Volc S, et al. Repositioning nutrition as central to development: a strategy for large-scale action. J Fam Welf. 2013;52(6):52-67.

11. Bhutta ZA, Das JK, Rizvi A, Gaff ey MF, Walker N, Susan H, et al. Evidencebased interventions for improvement of maternal and child nutrition: what can be done and at what cost? Lancet. 2013;382:452-77.
12. Bryce J, Coitinho D, Darnton-Hill I, Pelletier D, Pinstrup-Andersen P, Maternal Child Undernutrition Study Group. Maternal and child undernutrition: effective action at national level. Lancet. 2008;371(9611):510-26.

13. ICSU I. Review of the Sustainable Development Goals: the science perspective. Paris: International Council for Science (ICSU); 2015. http:// www.icsu.org/publications/reports-and-reviews/review-of-targets-for-thesustainable-development-goals-the-science-perspective-2015/SDG-Report. pdf. Accessed 18 May 2016.

14. Morris SS, Cogill B, Uauy R. Maternal Child Undernutrition Study Group. Effective international action against undernutrition: why has it proven so difficult and what can be done to accelerate progress? Lancet. 2008;371 (9612):608-21.

15. Van Royen K, Lachat C, Holdsworth M, Smit K, Kinabo J, Roberfroid D, et al. How can the operating environment for nutrition research be improved in sub-Saharan Africa? The views of African researchers. PLoS One. 2013;8(6):e66355. doi:10.1371/journal.pone.0066355.

16. Stirling A. Multi-criteria mapping: mitigating the problems of environmental valuation. In: Foster JB, editor. Valuing Nature?: Economics, ethics and environment. Taylor \& Francis; 2002. https://www.researchgate.net/ publication/272998931_Multicriteria_Mapping_mitigating_the_problems_ of_environmental_valuation. Accessed 18 May 2016.

17. Stirling A. Multi-criteria mapping: a detailed analysis manual. Manual Version. 2005;2:50-8. https://www.sussex.ac.uk/webteam/gateway/file. php?name=2014-11-swps-mcm-manual-1-0.pdf\&site=25. Accessed 18 May 2016.

18. Lachat C, Nago E, Roberfroid D, Holdsworth M, Smit K, Kinabo J, et al. Developing a sustainable nutrition research agenda in sub-Saharan Africa-findings from the SUNRAY project. PLoS Med. 2014;11(1):e1001593.

19. GOU. Uganda nutrition action plan 2011-2016. In: Scaling up multi-sectoral efforts to establish a strong nutrition foundation for Uganda's development. Kampala. 2011. http://scalingupnutrition.org/wp-content/uploads/2013/02/ Uganda_NutritionActionPlan_Nov2011.pdf. Accessed 13 Apr 2015.

20. Holdsworth M, Kruger A, Nago E, Lachat C, Mamiro P, Smit K et al. African stakeholders' views of research options to improve nutritional status in sub-Saharan Africa. Health Policy and Planning. 2014.1-12. doi:10.1093/ heapol/czu087.

21. Deckelbaum RJ, Palm C, Mutuo P, DeClerck F. Econutrition: implementation models from the millennium villages project in Africa. Food \& Nutrition Bulletin. 2006;27(4):335-42.

22. DeClerck FA, Fanzo J, Palm C, Remans R. Ecological approaches to human nutrition. Food \& Nutrition Bulletin. 2011;32(Supplement 1):41S-50.

23. Norheim F, Gjelstad IMF, Hjorth M, Vinknes KJ, Langleite TM, Holen T, et al. Molecular nutrition research —-the modern way of performing nutritional science. Nutrients. 2012:4(12):1898-944. doi:10.3390/nu4121898.

\section{Submit your next manuscript to BioMed Central} and we will help you at every step:

- We accept pre-submission inquiries

- Our selector tool helps you to find the most relevant journal

- We provide round the clock customer support

- Convenient online submission

- Thorough peer review

- Inclusion in PubMed and all major indexing services

- Maximum visibility for your research

Submit your manuscript at www.biomedcentral.com/submit
Biomed Central 